\title{
Comprehensive responses to sexual violence in East and Southern Africa: Lessons learned from implementation
}

\author{
Jill Keesbury \\ Population Council \\ lan Askew \\ Population Council \\ Monica Wanjiru \\ Population Council \\ Grace Chiyaba \\ Population Council \\ Kate Wilson
}

See next page for additional authors

Follow this and additional works at: https://knowledgecommons.popcouncil.org/departments_sbsr-rh

Part of the Domestic and Intimate Partner Violence Commons, International Public Health Commons, Maternal and Child Health Commons, Public Health Education and Promotion Commons, and the Women's Health Commons

How does access to this work benefit you? Let us know!

\section{Recommended Citation}

Keesbury, Jill, Ian Askew, Monica Wanjiru, Grace Chiyaba, Kate Wilson, and Felly Nkweto Simmonds. 2011. "Comprehensive responses to sexual violence in East and Southern Africa: Lessons learned from implementation," policy brief. Lusaka: Population Council. 


\section{Authors}

Jill Keesbury, Ian Askew, Monica Wanjiru, Grace Chiyaba, Kate Wilson, and Felly Nkweto Simmonds 


\section{Comprehensive Responses to Sexual Violence in East and Southern Africa: Lessons Learned from Implementation}

This brief was prepared by Jill Keesbury, lan Askew, Monica Wanjiru, Grace Chiyaba, Kate Wilson and Felly Nkweto Simmonds. It summarizes the publication: Keesbury, J. and I. Askew. 2010. "Comprehensive responses to gender based violence in low-resource settings: Lessons learnt from implementation," Lusaka: Population Council. www.popcouncil.org/pdfs/2010RH_CompRespGBV.pdf.

\section{How common is SGBV?}

Worldwide, an estimated 1 in every 3 women will experience some form of sexual or gender-based violence (SGBV) in their lifetime. ${ }^{1}$ Defined broadly, SGBV includes all forms of physical, psychological, economic and sexual violence (SV) that are related to the survivor's gender or gender role in a society or culture. ${ }^{2}$

Recent population-based surveys demonstrate that SGBV is common in the East and Southern Africa region and cuts across nationality, ethnicity, and socioeconomic status. SGBV affects a large proportion of women across the region; for example, 47 percent of Zambian women report ever experiencing physical violence and 59 percent of Ethiopian women report suffering SV (Figure 1). In many cases the perpetrator is known to the survivor, and intimate partners (such as husbands and boyfriends) are frequently identified as the perpetrators. Other data indicate that girls in the region frequently experience coerced sexual initiation which is often viewed as a normal part of relationships. ${ }^{3}$

\section{SGBV: A public health problem}

Women and girls who suffer SGBV are more likely to be infected with HIV, other sexually transmitted infections (STIs), and experience other reproductive health problems. Research indicates that the risk of HIV infection following forced sex is likely to be higher than following consensual sex, especially among children. ${ }^{9}$ This increased risk is especially pronounced in the high HIV-prevalence settings of sub-Saharan Africa ${ }^{10}$ Data from Demographic and Health Surveys have shown that women who have suffered violence are twice as likely to have an STI than women who have not. ${ }^{11}$ Moreover, a woman's risk of intimate partner violence (IPV) is increased if she discloses her HIV status to a partner,

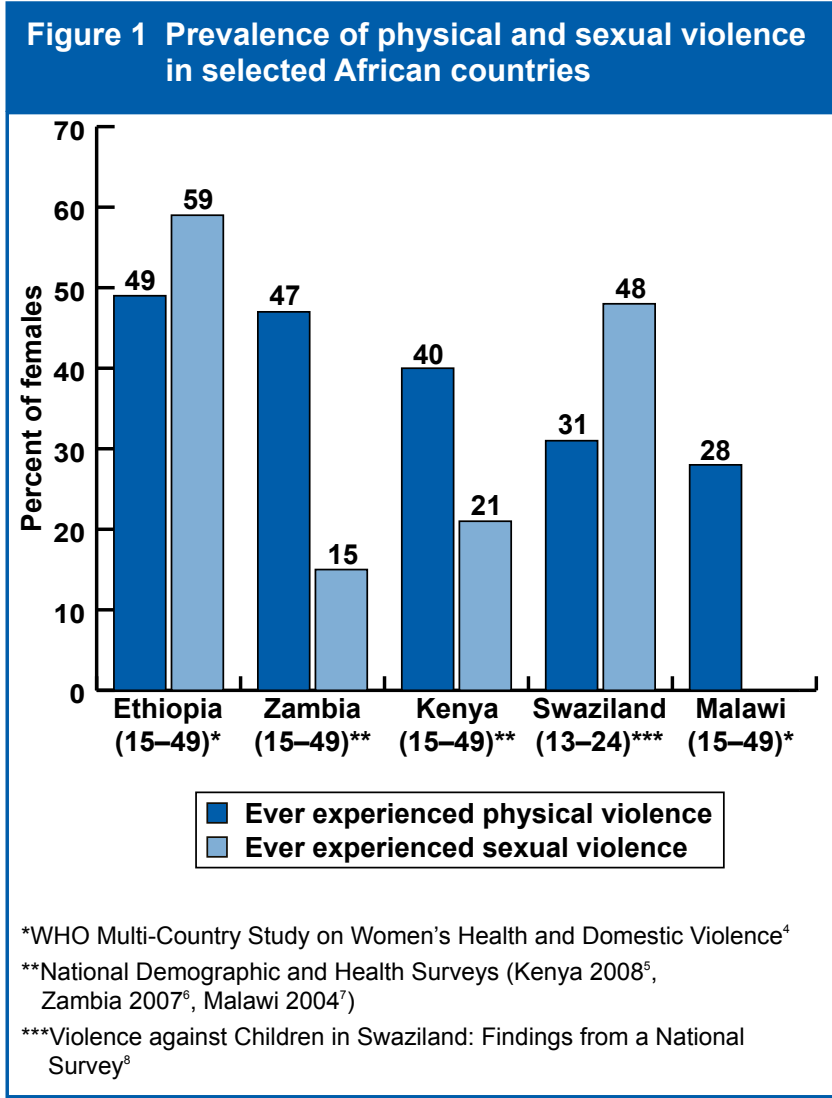

particularly in a discordant relationship ${ }^{12}$. Studies from across the world have found that girls and young women who previously experienced sexual coercion are significantly less likely to use condoms, and more likely to experience genital tract infection symptoms, unintended pregnancy and unsafe abortion. ${ }^{13}$ Women who experience IPV are more likely to use contraception secretly or prevented from using it, and are more likely to become pregnant as adolescents. ${ }^{14}$ Women who are abused during pregnancy are more likely to suffer depression, bleeding, and poor maternal weight gain. ${ }^{15}$ 
Over the past decade, many African countries have begun to recognize the importance of both preventing SGBV and responding to the needs of SGBV survivors at a national level. However, in the absence of a strong, regionally-relevant evidence base, these national programs have tended to adopt strategies that have proven successful in the high resource settings of Europe and North America. The feasibility and sustainability of such approaches is not well-established in countries where access to with limited financial and human resources.

\section{Towards a regional response to SGBV}

Many countries in Africa have recognised that they must address SGBV if they are to make progress toward human development goals, including significant reductions in poverty, HIV incidence, and maternal and infant mortality by 2015 . Organizations have tried various approaches to SGBV response, including preventing and reducing occurrence, linking to existing HIV/AIDS and sexual and reproductive health services, and strengthening the capacities of the police, judicial, and social services sectors to improve psychosocial support and legal actions. However, countries typically have concentrated on one or two sectors that focus on adult survivors' immediate needs without formal mechanisms for coordination or follow-up, or overarching national policies to hold all relevant sectors accountable. Until recently, there has been very little evidence in the region on how to effectively address SGBV taking into account local resource, cultural, and political realities.

Since 2006, the Population Council has provided technical assistance and conducted research to strengthen the evidence base on SGBV programming in sub-Saharan Africa. These activities have created an active network of partners from across sub-Saharan Africa, who are developing, implementing and evaluating core elements of a comprehensive, multisectoral response model (see Figure 2). This model incorporates the overlapping and complementary responsibilities of three core sectors: health, police and justice, and social service sectors. It also recognizes that survivors require access to all services, but that it may not be feasible, appropriate, or cost-effective to deliver all services in one location.

Today, the SGBV Network includes over twenty partners representing nine countries and regional bodies that provide technical support to implementing partners. Table 1 provides an overview of the partners and projects conducted under the Network, most of which are currently underway. SGBV Network activities, funded by the Swedish-Norwegian HIV/AIDS Team in Africa, will continue through 2012. Additional partner activities are supported by the United Nations Children's Fund East and Southern Africa Regional Office (Unicef EASRO), the United States Agency for Development, the US President's Emergency Plan for AIDS Relief (PEPFAR) and the United Nations Trust Fund for Women through Equality Now.

\section{Lessons learned on providing comprehensive services for survivors of SGBV}

Efforts by members of the network have advanced our understanding of SGBV in the region, identifying both effective program strategies and gaps in response efforts. The lessons summarized below are intended to serve as a resource for programme managers and policymakers throughout the region, and contribute to the emerging evidence base on such program strategies.

\section{Most survivors of sexual violence seeking services are children}

In all partner programs, the majority of survivors who sought care were aged under 18 years. In Kenya, children under 14 years comprised 67 percent of the

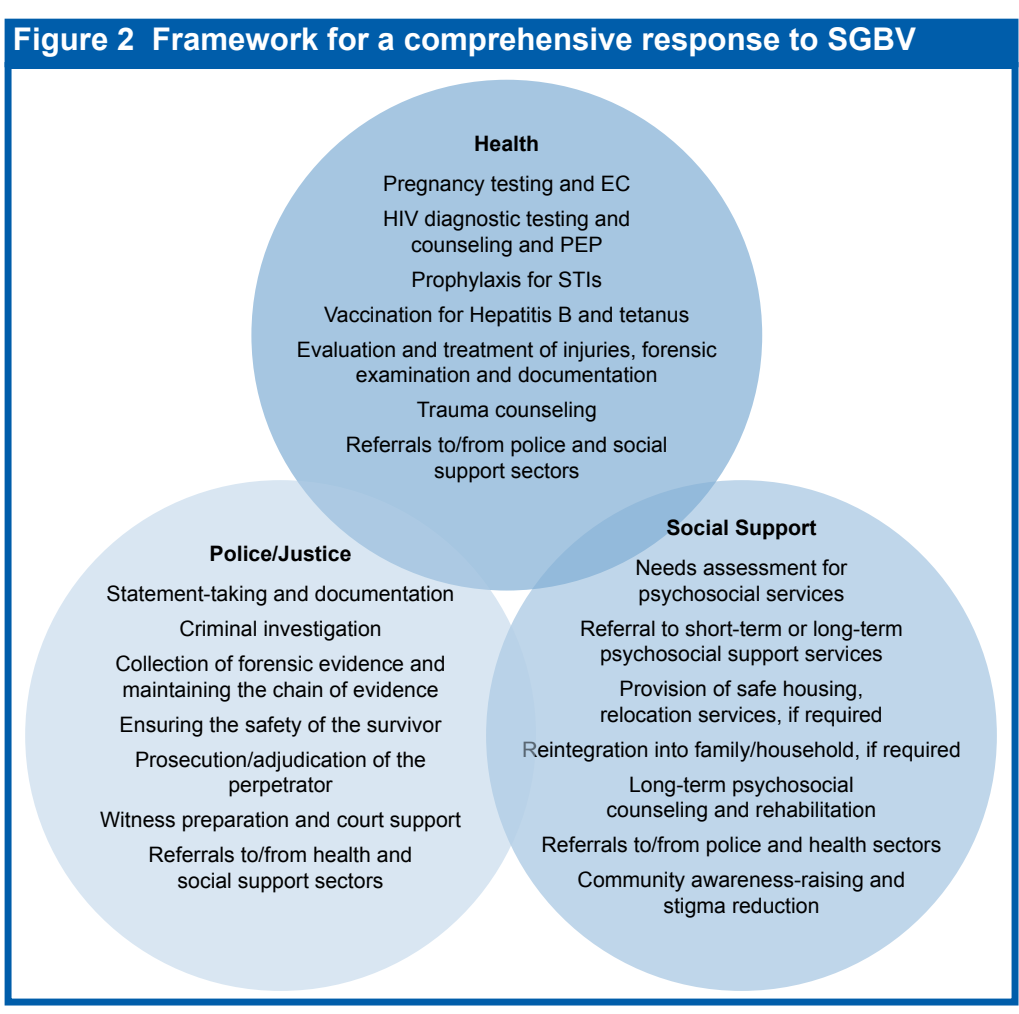




\begin{tabular}{|c|c|c|}
\hline Country & Project Title & Implementing Partners \\
\hline \multirow{3}{*}{ Zambia } & Copperbelt Model of Comprehensive Care (CMIC) & $\begin{array}{l}\text { Zambia Ministry of Health, Zambia Police Service, } \\
\text { Population Council }\end{array}$ \\
\hline & $\begin{array}{l}\text { Our girls, our future: Building synergy to end violence } \\
\text { against girls in Zambia }\end{array}$ & $\begin{array}{l}\text { Equality Now, Tisunge Ana Athu Akazi Coalition (TAAAC) } \\
\text { members }\end{array}$ \\
\hline & $\begin{array}{l}\text { Review of multi-sectoral response services (one-stop } \\
\text { centers) for SGBV response }\end{array}$ & Unicef, Care International, University of Zambia \\
\hline \multirow[b]{3}{*}{ South Africa } & Refentse Phase II* & Tshwaranang Legal Advocacy Centre (TLAC) \\
\hline & $\begin{array}{l}\text { Sustainable implementation of a multi-sectoral } \\
\text { prevention and support strategy }\end{array}$ & Thohoyandou Victim Empowerment Program (TVEP) \\
\hline & $\begin{array}{l}\text { Improving access to comprehensive post rape care } \\
\text { (adults and children) and occupational exposure of } \\
\text { PEP }\end{array}$ & $\begin{array}{l}\text { Department of Health, Department of Correctional Services, } \\
\text { South African National Defence Force, South African Police } \\
\text { Services, Democratic Nursing Organization of South Africa, } \\
\text { Foundation for Professional Development, AgriAIDS, } \\
\text { Ubuntu Institute, ANOVA, University of Witwatersrand, } \\
\text { Musina Migrants Forum }\end{array}$ \\
\hline \multirow[b]{2}{*}{ Kenya } & $\begin{array}{l}\text { Improving 'custody-of-evidence' chain for post-rape } \\
\text { care services in Kenya }\end{array}$ & Liverpool VCT, Care and Treatment (LVCT) \\
\hline & $\begin{array}{l}\text { Assessing the acceptability and feasibility of } \\
\text { screening for IPV in public health care settings in } \\
\text { Kenya }\end{array}$ & Kenyatta National Hospital, Population Council \\
\hline Malawi & $\begin{array}{l}\text { Towards a multisectoral approach on SGBV in } \\
\text { Malawi }\end{array}$ & $\begin{array}{l}\text { Malawi Police Service, Ministry of Health, Human Rights } \\
\text { Resource Centre }\end{array}$ \\
\hline Zimbabwe & Musasa Project* & Zimbabwe National Family Planning Association \\
\hline Ethiopia & $\begin{array}{l}\text { Nationalization of guidelines on comprehensive } \\
\text { management of SGBV* }\end{array}$ & $\begin{array}{l}\text { Ethiopian Society of Obstetricians and Gynaecologists } \\
\text { (ESOG) }\end{array}$ \\
\hline Swaziland & $\begin{array}{l}\text { Preventing SGBV among in-school girls and } \\
\text { developing national guidelines for a multi-sectoral } \\
\text { response to SGBV }\end{array}$ & Swaziland Action Group Against Abuse (SWAGAA) \\
\hline Rwanda & $\begin{array}{l}\text { PEPFAR Special Initiative on Gender-Based } \\
\text { Violence* }\end{array}$ & $\begin{array}{l}\text { IntraHealth, Drew Cares International, the Rwanda } \\
\text { Defense Force, The International Centre for AIDS Care and } \\
\text { Treatment Programs/Columbia University, Catholic Relief } \\
\text { Services, AIDS Relief }\end{array}$ \\
\hline Uganda & $\begin{array}{l}\text { PEPFAR Special Initiative on Gender-Based } \\
\text { Violence* }\end{array}$ & $\begin{array}{l}\text { Makerere University Joint AIDS Program, Northern Uganda } \\
\text { Malaria, Tuberculosis and HIVIAIDS Program, Uganda } \\
\text { People's Defence Force }\end{array}$ \\
\hline \multicolumn{3}{|c|}{ South-south technical assistance network partners } \\
\hline & Partner & Activities \\
\hline \multirow{5}{*}{ Regional } & Unicef East and Southern Africa Regional Office & $\begin{array}{l}\text { Provides technical support to Unicef Country Offices and } \\
\text { partners on SGBV programming }\end{array}$ \\
\hline & $\begin{array}{l}\text { East, Central and Southern Africa Health } \\
\text { Commission }\end{array}$ & $\begin{array}{l}\text { Intergovernmental health policy body implementing a } \\
\text { regional framework on SGBV }\end{array}$ \\
\hline & Sonke Gender Justice Network & $\begin{array}{l}\text { Regional network that promotes male involvement in SGBV } \\
\text { prevention efforts }\end{array}$ \\
\hline & Sexual Violence Research Initiative (SVRI) & $\begin{array}{l}\text { International network that promotes research and training } \\
\text { on SGBV }\end{array}$ \\
\hline & Raising Voices & $\begin{array}{l}\text { Regional network on community- based approaches to } \\
\text { SGBV prevention }\end{array}$ \\
\hline \multirow{2}{*}{ South Africa } & Medical Research Council (MRC) & $\begin{array}{l}\text { Hosts a regional program on training and guideline } \\
\text { development for clinical management of SGBV }\end{array}$ \\
\hline & Greater Nelspruit Rape Initiative Project (GRIP) & $\begin{array}{l}\text { Community-based victim empowerment project, which } \\
\text { supports survivors of SV and IPV }\end{array}$ \\
\hline Kenya & International Centre for Reproductive Health & $\begin{array}{l}\text { Supports the Coast General Hospital's GBV recovery } \\
\text { center }\end{array}$ \\
\hline
\end{tabular}


cases reported in the Coast General Hospital's genderbased violence recovery center; in Zambia and South Africa, the proportions were 49 percent and 31 percent, respectively. In Ethiopia, 37 percent of the reported cases were children under age 11 . Despite the large number of children and youth who report for care, most programmes do not offer child-friendly services, largely due to the lack of providers trained in examining, documenting, managing and referring cases of child sexual abuse. As a result, in many settings children receive inadequate care and support. In one South African program, girls under age 16 were 23 percent less likely to receive PEP for HIV than adults. Experiences indicate that adultoriented programs cannot adequately address the needs of children and youth, and that age-specific strategies are needed urgently.

Recent versions of national SGBV guidelines from Kenya and Zambia serve as examples of how countries can begin to meet these needs. The National Guidelines on the Management of Sexual Violence in Kenya (2009) include special provisions for history taking of children, genitoanal examination of girls and boys, and PEP regimens for children. ${ }^{18}$ The National Guidelines for the Multidisciplinary Management of SGBV in Zambia (2010 draft) also include guidance on providing psychosocial care for children and their parents. ${ }^{19}$ In South Africa, a special evidence collection kit has been developed solely for use with child survivors.

\section{Community-level barriers commonly undermine care-seeking}

It is widely believed that only a small proportion of those who experience violence seek any type of institutional care. In Swaziland, only 7 percent of child sexual abuse survivors reported seeking counselling, police response or health care services. ${ }^{8}$ Another study in Uganda and Rwanda identified key barriers to accessing such care: a preference of survivors and their families for resolving the issue at home, which was attributed either to deference or to traditional culture; fear of stigma if the case is made public; the family's preference to seek compensation directly from the perpetrator rather than through the criminal justice system; a lack of awareness of where to go for services and the procedures involved; inability to pay for transportation and service fees; long distances to the nearest service point; and threats by the perpetrator. Lengthy and inefficient procedures and unfriendly service providers also discouraged survivors from seeking help from police stations and health facilities. ${ }^{20}$

\section{Guidelines are necessary, but do not ensure comprehensive service delivery}

While national guidelines are essential in the provision of comprehensive care to survivors of SV, a multi-sectoral approach and the engagement of a wide range of relevant actors is equally important. To spur the development and implementation of national guidelines, governments and partners benefit tremendously from the efforts of "champions", individuals or agencies within and outside the government who actively follow-up to ensure that guidelines are implemented properly. In Uganda and Malawi, it took the efforts of such partners to ensure that the existing guidelines were actively implemented.

\section{A variety of approaches can be used to provide quality, comprehensive care}

Comprehensive care can be provided in different settings outside of a 'one-stop' shop approach, where all services are provided in one location. Partners have demonstrated that a range of sustainable, effective approaches to providing comprehensive care exist, and that these can be effectively organized in a variety of ways depending on the context and capacity of existing services. Some models build on existing infrastructure and require only
Table 2 Models of comprehensive care

\begin{tabular}{|c|c|c|}
\hline Partner & Model & Key outcomes \\
\hline TVEP, South Africa & $\begin{array}{l}\text { Care provided at dedicated one-stop trauma centers } \\
\text { adjoining district hospitals, independently operated by } \\
\text { TVEP }\end{array}$ & $\begin{array}{l}82 \% \text { of clients received } 28 \text { days of PEP, } 55- \\
92 \% \text { completed course }\end{array}$ \\
\hline $\begin{array}{l}\text { Tintswalo Hospital, } \\
\text { South Africa }\end{array}$ & $\begin{array}{l}\text { Care integrated within facility through development of } \\
\text { management protocols, nurses provide most services }\end{array}$ & $\begin{array}{l}68 \% \text { of clients received } 28 \text { days of PEP, } 81 \% \\
\text { received } \mathrm{EC}\end{array}$ \\
\hline $\begin{array}{l}\text { Kamuzu Central } \\
\text { Hospital, Malawi }\end{array}$ & $\begin{array}{l}\text { SV services centralized in one hospital unit (STI clinic } \\
\text { during business hours, obstetrics and genecology } \\
\text { ward during weekends) }\end{array}$ & $\begin{array}{l}95 \% \text { of clients received } 28 \text { days of PEP, } 59 \% \\
\text { received EC }\end{array}$ \\
\hline CMIC, Zambia & $\begin{array}{l}\text { Police officers provide emergency contraception, } \\
\text { referrals for further health care }\end{array}$ & $\begin{array}{l}\text { Reporting to police increased by } 48 \%, 93 \% \\
\text { of survivors seen by police referred to health } \\
\text { facility }\end{array}$ \\
\hline
\end{tabular}


minimal inputs in training and supplies; in others, new systems and infrastructure must be established. Table 2 summarizes some of the different models and outcomes implemented by SGBV Network Partners.

\section{Ensuring adherence to HIV post-exposure prophylaxis remains a key challenge}

While notable progress has been made in increasing access to PEP, efforts to ensure compliance with the full 28-day regimen remain more limited. Loss to follow-up is consistently identified as a key factor in undermining efforts to encourage and monitor PEP adherence. Across settings, barriers consistently included client reluctance to seek follow-up due to stigma, trauma, cost, and availability of transportation. Within the facilities, provider work-loads and inadequate case management systems make it difficult to monitor follow-up care. In South Africa, TVEP has achieved relatively high adherence rates (55-92 percent) through intensive client counselling and follow-up at home, although the model is costly to maintain. Partners in South Africa's Tintswalo Hospital found that providing clients with the full 28-day dose of PEP during the first visit increased the proportion of survivors who completed the course by 38 percent.

\section{Provider capacity remains an important barrier to quality, comprebensive care}

In many public facilities across the continent, there is an acute shortage of staff, creating long waiting times and full waiting areas, particularly in emergency departments. These conditions are extremely daunting for an SV survivor and mean that providers cannot offer the quality of care they would like to, or that no trained personnel are available. Quality of care is also undermined by negative attitudes toward survivors of SV. As members of society, many doctors, nurses, police officers and other support personnel may hold common misperceptions about survivors that reinforce stigma, shame, and victim-blaming.

\section{Requirements that doctors collect forensic evidence undermine a survivor's access to justice and bealth care}

When properly collected and processed, medical evidence can be the basis of successful prosecution of sex offenders. However, the limited ability of medical systems to collect such evidence has been identified as a key barrier to quality services. In many countries, law or practice dictates that only doctors are allowed to collect and document such evidence for use in legal proceedings. This can create significant delays in receiving emergency
Other Population Council resources on SGBV

A step-by-step guide to strengthening sexual violence services in public health facilities: Lessons and tools from Sexual Violence Services in Africa www.popcouncil.org/pdfs/2010HIV_PEPFAR_ SGBV_Toolkit.pdf

The prevention and management of HIV and sexual and gender-based violence: responding to the needs of survivors and those at-risk. www.popcouncil.org/pdfs/2011_HIV SGBVBrief.pdf

Additional information on the Population Council's SGBV work can be found at www.popcouncil. org/topics/gbv.asp

medical services, such as PEP and EC, because survivors who report to lower-level health facilities are often referred to hospitals with doctors on duty. At higher-level facilities, doctors have many other duties, may be overworked, not available when needed, and are less likely than nurses to fully document cases. In Kenya, LVCT improved the collection of medico-legal evidence in hospitals by developing an algorithm to guide the collection, storage and documentation of such evidence, and by training a wide range of cadres of medical staff in the procedures. In South Africa, the expanded use of forensic nurses demonstrates that lower-level cadres can effectively contribute to the collection of medical evidence, although problems remain with their willingness to present evidence in court.

\section{Comprehensive care services must include functional linkages between bealth and police services}

In many countries, SGBV survivors report first to the police and often do not seek further health or support services. Strong referral networks are therefore essential to ensure survivors receive the health care they need, including the prevention of pregnancy and HIV transmission within the 72-hour window period for EC and PEP. One strategy for improving such linkages was tested in Zambia, where the police provided the survivors with EC and referrals to health facilities for further management and collection of evidence. This initiative led to improved reporting and referral rates, and strong collaboration between the two sectors. It is now being scaled-up nationally across Zambia and piloted in Malawi through technical assistance from Zambian partners. 


\section{Psychosocial support to survivors is important, but often lacking}

Psychosocial support for SGBV survivors should include counselling, provision of safe houses and community efforts to reduce stigma. Survivors recognize the value of such services, with over half of TVEP's clients requesting to join support groups. However, such care is lacking in most low-resource settings due limited provider capacity, time, and evidence of what approaches are most effective. Safe houses and other temporary refuges are critical in cases of IPV and child sexual abuse, but are costly to maintain and virtually non-existent in Africa outside of large towns. Experiences of network members demonstrate that training in basic interpersonal and counselling skills can substantially improve a survivor's experience. In South Africa, nurses at Tintswalo hospital were successfully trained to provide basic counselling and trauma debriefing skills, with 99 percent of survivors reporting that the counselling was helpful.

\section{Conclusion and recommendations}

Network partners have significantly increased the evidence base on program responses to SGBV in subSaharan Africa. A range of successful approaches have been demonstrated for improving comprehensive services within the health, police, legal and social service sectors, but it has also underscored that there is still much to be done in ensuring that these services are adequately and equitably provided across the region.

Based on these findings, the following actions are recommended to improve programs and policies across the region:

- Special guidance, training and services are needed to adequately respond to the needs of child survivors, who currently constitute the majority of those seeking care in most countries.

- Community-level interventions must be implemented to reduce barriers to care-seeking and create awareness of the services available to survivors.

- Governments should consider an inclusive, participatory, and multi-sectoral approach to guideline development and dissemination to encourage active implementation.

- Health facilities should actively integrate services in at least one unit equipped with adequately trained providers and necessary supplies, and ensure that services are available on a 24-hour basis.
- Training for health care workers, police and other support personnel must explicitly address commonly held biases against SGBV survivors, basic counselling and interpersonal skills.

- National policies and practices should be reviewed to ensure that nurses and clinical officers can collect medico-legal evidence and provide testimony in court.

- More evidence on cost-effective, sustainable and culturally-appropriate approaches for providing psychosocial support in low-resource settings is needed.

There is also a need to explore other dimensions of SGBV services. In general, intimate partners are the most commonly reported perpetrators of sexual violence against women and children; however, most response services have focused on addressing the acute needs of survivors without consideration of the specific issues and challenges of violence within a marriage, family or other domestic relationship. Additional research is needed to identify appropriate strategies for ethically identifying and meeting the needs of this large, and often silent, population. Just as importantly, more documentation is needed on successful strategies for preventing all forms of SGBV before it occurs. The Network is continuing to explore these issues in its current phase of programming. 


\section{References}

1. Heise L., M. Ellsberg and M. Gottemoeller, "Ending violence against women," Population Reports, Series L, No. 11., cited by International Women's Health Coalition, "Triple jeopardy: Female adolescence, sexual violence and HIV/AIDS” (June 2008).

2. IGWG of USAID. "Addressing gender-based violence through usaid's health programs: A guide for health sector program officers." Washington, DC (2006).

3. American Foundation for AIDS Research. "Gender-based violence and HIV among women: assessing the evidence," Issue Brief no.3 (2005).

4. García-Moreno, C. et al. WHO multi-country study on women's health and domestic violence against women: Initial results on prevalence, health outcomes and women's Responses. Geneva, Switzerland: World Health Organization (2005).

5. National Bureau of Statistics (Kenya) and ORC Macro. Kenya Demographic Health Survey, 2008. Calverton, Maryland (2010).

6. Central Statistical Office et al. Zambia Demographic and Health Survey, 2007. Calverton, Maryland (2009).

7. National Statistical Office Malawi and ORC Macro. Malawi Demographic Health Survey, 2004. Calverton, Maryland (2005).

8. Reza, A. et al. "Violence against children in Swaziland: Findings from a national survey." Centers for Disease Control and Prevention and Swaziland United Nations Children's Fund (2007).

9. Speight, C.G. et al. "Piloting post-exposure prophylaxis in Kenya raises specific concerns for the management of childhood rape." Transactions of the Royal Society of Tropical Medicine and Hygiene (2006).

10. Ellis, J.C. et al. "Introduction of HIV post-exposure prophylaxis for sexually abused children in Malawi," Arch Dis Child 90:1297-1299 (2005).
11. Kishor, S., and K. Johnson. Profiling Domestic Violence-A Multi-Country Study. ORC Macro (2004).

12. Fonck, K. et al. "Increased risk of women experiencing physical partner violence in Nairobi, Kenya," AIDS and Behavior 9(3): 335-339 (2005).

13. Campbell, R. and T. Self. "The impact of rape on women's sexual health risk behaviors," Health Psychology 23(1): 67-74 (2004).

14. Garcia-Moreno, C., "Dilemmas and opportunities for an appropriate health-service response to violence against women," Lancet 359: 1509-1514 (2002).

15. Campbell, J., C. Garcia-Moreno, and P. Sharps, "Abuse during pregnancy in industrialized and developing countries,” Violence Against Women 10(7): 770-789 (2004).

16. Asling-Monemi, K. et al. "Violence against women increases the risk of infant and child mortality: A case study in Nicaragua," The Bulletin of the World Health Organization, 81:10-18 (2003).

17. E. Valladares et al., "Physical partner abuse during pregnancy: A risk factor for low birth weight in Nicaragua," Obstetrics \& Gynecology 100(4): 700-705 (2002).

18. Government of Kenya, Ministries of Public Health and Sanitation and Medical Services. National Guidelines on the Management of Sexual Violence in Kenya. Nairobi: Kenya (2010).

19. Government of the Republic of Zambia (Ministries of Gender and Women Affairs, Health, Home Affairs, Community Development and Social Services). Guidelines for the Multidisciplinary Management of Sexual and GenderBased Violence in Zambia. (March 2010 Draft).

20. Elson, Lynne and Jill Keesbury. "PEPFAR Special Initiative on Sexual and Gender-Based Violence: Baseline Report.” Lusaka: Population Council. (2010). 
The Population Council conducts research worldwide to improve policies, programs, and products in three areas: HIV and AIDS; poverty, gender, and youth; and reproductive health.

Population Council/Zambia

Mwinilunga Road, Plot 4108, Sunningdale-Kabulonga

Lusaka

Zambia

10101

www.popcouncil.org

Suggested citation: Keesbury, Jill , lan Askew, Monica Wanjiru, Grace Chiyaba, Kate Wilson and Felly Nkweto Simmonds. 2011. "Comprehensive responses to sexual violence in East and Southern Africa: Lessons learned from implementation," Lusaka: Population Counicl.

(c) 2011 The Population Council, Inc.

Any part of this publication may be photocopied without permission from the publisher provided that copies are distributed without charge and that full source citation is provided. The Population Council would appreciate receiving a copy of any materials in which the text is used. 